NBER WORKING PAPER SERIES

\title{
DO WE REALLY NEED A NEW INTERNATIONAL MONETARY COMPACT?
}

\author{
Maurice Obstfeld \\ Kenneth Rogoff \\ Working Paper 7864 \\ http://www.nber.org/papers/w7864 \\ NATIONAL BUREAU OF ECONOMIC RESEARCH \\ 1050 Massachusetts Avenue \\ Cambridge, MA 02138 \\ August 2000
}

\begin{abstract}
Alberto Alesina, Juan Carlos Hallak, and Nouriel Roubini provided helpful comments on an earlier draft of this paper. We thank the National Science Foundation for financial support. The views expressed herein are those of the authors and not necessarily those of the National Bureau of Economic Research.

(C) 2000 by Maurice Obstfeld and Kenneth Rogoff. All rights reserved. Short sections of text, not to exceed two paragraphs, may be quoted without explicit permission provided that full credit, including $\odot$ notice, is given to the source.
\end{abstract}


Do We Really Need a New International Monetary Compact?

Maurice Obstfeld and Kenneth Rogoff

NBER Working Paper No. 7864

August 2000

JEL No. E42, F41, F42

\begin{abstract}
In recent years, many countries have instituted monetary reforms aimed at improving antiinflation credibility. Is it a problem, however, that international welfare spillover effects seldom receive much consideration in the design of monetary reforms? Surprisingly, the answer may be no. Under plausible conditions, as domestic rules improve and international financial markets become more complete, the Nash and cooperative monetary rule setting games converge. We base our analysis on a utility-theoretic sticky-wage (new open economy macroeconomics) model; the question we pose simply could not have been adequately formulated using earlier models of monetary cooperation.
\end{abstract}

\author{
Maurice Obstfeld \\ Economics Department \\ 549 Evans Hall, \#3880 \\ U.C. Berkeley \\ Berkeley, CA 94720-3880 \\ and NBER \\ obstfeld@econ.berkeley.edu \\ Kenneth Rogoff \\ Economics Department \\ Littauer Center \\ Harvard University \\ Cambridge, MA 02138-3001 \\ and NBER \\ krogoff@harvard.edu
}




\section{Introduction}

Over the past ten to fifteen years, OECD governments have taken enormous strides in mitigating the "commitment" problem in monetary policy and, as a result, world-wide inflation rates have dropped dramatically. Nowadays, academic discussions of optimal monetary policy increasingly focus on oldfashioned stabilization considerations, rather than anti-inflation credibility. ${ }^{1}$ The international dimensions of monetary stabilization, however, have largely been ignored. Is it a problem that countries design their rule-based domestic monetary institutions unilaterally, ignoring international spillover effects? Is it possible that the current system produces, say, excessive attention to inflation stabilization and inadequate attention to output stabilization, when viewed from a global perspective?

We are not the first to address this question. Persson and Tabellini (1995, 2000) have shown how, in principle, international cooperation in designing domestic fiscal and monetary policy institutions can lead to improved global outcomes, even absent any binding international agreements. They themselves emphasize, however, that the ad hoc Keynesian framework they use for studying monetary policy is far less satisfactory than the more rigorous framework they employ for fiscal policy (see Persson and Tabellini 1995, p. 1976). As Corsetti and Pesenti (2000) note, the recent advent of "new open economy macroeconomics" offers the promise of being able to address this deficiency, and analyze strategic issues in monetary cooperation with the same level of rigor that is already routine in the evaluation of fiscal policy. This paper aims to begin to fulfill that promise.

We find that once one models the microfoundations of the wage setting process and national welfare, it becomes apparent that the gains to cooperation in the setting of international monetary rules may quite possibly be of the second order. The basic intuition relies on an envelope condition. In special cases where the cooperative policy rules turn out to mimic the flexible-wage allocation then, in our model, individual countries have nothing to gain by defecting to another domestic policy rule. In more general cases, where the cooperatively set rules balance the need to offset multiple distortions (including sticky nominal wages and inefficient international risk sharing), the welfare gains from international cooperation still turn out to be exceedingly small in comparison with the gains to stabilization policy, at

\footnotetext{
${ }^{1}$ See, for example, Svensson (2000) and the references therein.
} 
least for what we view as a broad range of plausible parameters.

Our results are important because, as both Persson and Tabellini (1995) and Drazen (2000) emphasize, the kinds of institutional reform that might alleviate international as well as domestic monetary policy credibility problems appear to be a good deal more fragile than those needed to deal with domestic credibility reforms alone. Although it is true that Jensen (2000) has developed an arguably more plausible implementation strategy than in the original Persson and Tabellini (1995) formulation, our paper still throws open the question of whether the gains to cooperative rule setting are likely to be quantitatively significant. In a world where the question of international monetary reform continues to be actively debated at the highest policy levels, the issue would certainly seem to be an important one.

Sections 2 through 4 develop a generalization of the new open economy macroeconomics models of Obstfeld and Rogoff (1998, 2000), extended to incorporate the case of incomplete risk sharing. In sections 5 and 6 , we explore the relationship between the cooperative and non-cooperative rule setting games, and section 7 discusses the relationship of our work to the previous literature. Section 8 concludes.

\section{A Two-Country Sticky-Wage Model}

In this section, we extend the two-country model of Obstfeld and Rogoff (2000), adapted to allow us to focus on several aspects of international policy coordination. Given that the model itself is not our main focus, and that its various building blocks are all relatively familiar, we will only present the essential features. The reader should especially note that whereas nominal wages are set optimally one period in advance in the model, firms can set prices flexibly. Admittedly, the model abstracts from realistic features such as overlapping long-term nominal contracts, but it has the advantage of yielding tractable closed form solutions that greatly facilitate our analysis of policy coordination.

\subsection{Country size and market structure}

The world economy consists of two equally-sized countries, Home and Foreign. Firms produce differentiated goods out of differentiated labor inputs indexed by $[0,1]$. Home produces differentiated tradable goods on the inter- 
val $[0,1]$, while Foreign's tradables are indexed by $(1,2]$. In addition, each country produces an array of differentiated nontraded goods indexed by $[0,1]$.

\section{$2.2 \quad$ Firms}

Let $Y(i)$ denote output of differentiated good $i$ and $L(i, j)$ the demand for labor input $j$ by producer $i$. Home traded goods production is given by

$$
Y_{\mathrm{H}}(i)=\left[\int_{0}^{1} L_{\mathrm{H}}(i, j)^{\frac{\phi-1}{\phi}} \mathrm{d} j\right]^{\frac{\phi}{\phi-1}} .
$$

Home nontraded goods production is identical with $Y_{\mathrm{N}}(i)$ and $L_{\mathrm{N}}(i, j)$ replacing $Y_{\mathrm{H}}(i)$ and $L_{\mathrm{H}}(i, j)$ in the above expression. The Foreign production functions are also identical (with the same substitution elasticity $\phi$ ) except that Foreign-produced tradables, denoted $Y_{\mathrm{F}}(i)$, are indexed by $i \in(1,2]$. As our analysis focuses on a single contracting period, we omit time subscripts.

As usual, firm $i$ 's demand for labor of type $j$ is

$$
L(i, j)=\left[\frac{W(j)}{W}\right]^{-\phi} Y(i),
$$

where $W(j)$ is the nominal wage of worker $j$ and $W$ is the exact production-

based index of wages, $W=\left[\int_{0}^{1} W(j)^{1-\phi} \mathrm{d} j\right]^{\frac{1}{1-\phi}}$.

\subsection{Individual preferences}

A Home individual of type $i$ maximizes the expected value of

$$
U^{i}=\frac{\left(C^{i}\right)^{1-\rho}}{1-\rho}+\chi \log \frac{M^{i}}{P}-\frac{K}{\nu}\left(L^{i}\right)^{\nu},
$$

where $\rho>0$ is the (constant) coefficient of relative risk aversion and

$$
L^{i} \equiv \int_{0}^{1}\left[L_{\mathrm{H}}(i, j)+L_{\mathrm{N}}(i, j)\right] \mathrm{d} j
$$

and $\nu>1$. In (3), $K$ is a random shift in the marginal disutility of work effort that can be interpreted as a (negative) country-wide Home productivity 
shock. $^{2}$ The Foreign productivity shock, $K^{*}$, is distributed symmetrically, though not necessarily independently. The aggregate money supplies, $M$ and $M^{*}$, are the other exogenous random variables that impinge on the economy.

In Obstfeld and Rogoff (2000) we focused on the case of log consumption preferences $(\rho=1)$, but here we generalize to an arbitrary positive $\rho$.

For any person $i$ the overall real consumption index $C$ is given by $C=$ $C_{\mathrm{T}}^{\gamma} C_{\mathrm{N}}^{1-\gamma} / \gamma^{\gamma}(1-\gamma)^{1-\gamma}$, where preferences over Home and Foreign traded goods are given by $C_{\mathrm{T}}=2 C_{\mathrm{H}}^{1 / 2} C_{\mathrm{F}}^{1 / 2}$. Foreign preferences are identical. The consumption subindexes for $C_{\mathrm{H}}, C_{\mathrm{F}}$, and $C_{\mathrm{N}}$ are constant elasticity aggregates [analogous to (1)] with identical elasticity $\theta$.

Domestic-currency price indexes for $C_{\mathrm{H}}, C_{\mathrm{F}}$, and $C_{\mathrm{N}}$ are isomorphic to the wage index given just after eq. (2), with the consumption substitution elasticity $\theta$ in place of $\phi$. The domestic-currency price index for overall real consumption $C$ is $P=P_{\mathrm{T}}^{\gamma} P_{\mathrm{N}}^{1-\gamma}$, and the price index for tradable consumption $C_{\mathrm{T}}$ is $P_{\mathrm{T}}=P_{\mathrm{H}}^{\frac{1}{2}} P_{\mathrm{F}}^{\frac{1}{2}}$.

Isomorphic to the labor demand eq. (2) are the Home and Foreign consumer demands for individual goods, which depend on relative price with a constant elasticity $\theta$; e.g., Home demand for a typical Home tradable $h$ is

$$
C_{\mathrm{T}}(h)=\left[\frac{P_{\mathrm{T}}(h)}{P_{\mathrm{H}}}\right]^{-\theta} C_{\mathrm{H}} .
$$

Given the assumed unit elasticity of substitution between Home and Foreign goods, and between traded and nontraded goods, we have: $C_{\mathrm{H}}=\frac{1}{2}\left(P_{\mathrm{H}} / P_{\mathrm{T}}\right)^{-1} C_{\mathrm{T}}$, $C_{\mathrm{F}}=\frac{1}{2}\left(P_{\mathrm{F}} / P_{\mathrm{T}}\right)^{-1} C_{\mathrm{T}}, C_{\mathrm{T}}=\gamma\left(P_{\mathrm{T}} / P\right)^{-1} C$, and $C_{\mathrm{N}}=(1-\gamma)\left(P_{\mathrm{N}} / P\right)^{-1} C$. The first-order condition governing money demand is:

$$
\frac{M^{i}}{P}=\chi\left(C^{i}\right)^{\rho} .
$$

\subsection{Asset markets and budget constraints}

The only internationally traded asset is a real bond indexed to the composite traded good $C_{\mathrm{T}}$. Thus, domestic firms are entirely domestically owned. We choose not to resort to the popular contrivance of assuming complete

\footnotetext{
${ }^{2}$ One can think of $L$ as denoting efficiency labor rather than hours worked $H$, with $H=K^{1 / \nu} L$. Our analysis does not allow for sectoral domestic productivity shocks but that simplification is not essential.
} 
Arrow-Debreu contracts internationally since, in general, the presence of such contracts would significantly complicate interpretation of our later strategic results. ${ }^{3}$ Also, as we have argued elsewhere (Obstfeld and Rogoff 1995), the marriage of complete contracts and sticky prices into the same model is an uneasy one. In any event, when $\rho=1$, our economy will turn out to mimic one with complete asset markets.

Given our assumed asset market structure, a Home individual faces the intertemporal budget constraint

$$
M^{i}+P C^{i}=M_{0}^{i}+P T+W(i) L^{i}+\int_{0}^{1}\left[\Pi_{\mathrm{H}}(j)+\Pi_{\mathrm{N}}(j)\right] \mathrm{d} j .
$$

Here, PT denotes per capita nominal transfers from the Home government, while $\Pi_{\mathrm{H}}$ and $\Pi_{\mathrm{N}}$ denote dividend (profit) payments by firms. Finally, the government issues money in lump-sum transfers, so that $P T=M-M_{0}$.

\section{Equilibrium Price and Wage Setting}

We assume that workers set nominal wages a period in advance and, ex post, supply the amount of labor that firms demand at the posted nominal wage. The fact that wages are set optimally in response to the government's choice of monetary rule will turn out to be quite important for our later discussion of policy coordination, so we begin by exploring the wage decision.

\subsection{Optimal wage setting}

Use the individual's budget constraint (5) to eliminate $C^{i}$ in expected utility $\mathrm{E} U^{i}$, then substitute for labor supply using eq. (2). One derives the firstorder condition for the optimal preset nominal wage $W(i)$ :

$$
W(i)=\left(\frac{\phi}{\phi-1}\right) \frac{\mathrm{E}\left\{K\left(L^{i}\right)^{\nu}\right\}}{\mathrm{E}\left\{\frac{L^{i}}{P}\left(C^{i}\right)^{-\rho}\right\}} .
$$

\footnotetext{
${ }^{3}$ For complete nominal contract models, see Bergin and Feenstra (2000) or Chari, Kehoe, and McGrattan (1998). If one were to introduce Arrow-Debreu contracts into the strategic setting we are about to explore, it would be necessary to assume that they are indexed to all conceivable changes in the monetary regime; otherwise changes in monetary policy rules could reallocate wealth across countries, and agents would wish to insure against such events.
} 
Absent uncertainty, eq. (6) would simply give the marginal utility of the real wage as a fixed markup $\phi /(\phi-1)$ over the marginal disutility of labor.

\subsection{Price setting, the real exchange rate, and the terms of trade}

As we have already emphasized, monopolistic firms can freely change their products' prices. However, with constant and identical elasticities of demand at home and abroad, price markups over cost turn out to be the same in both countries, so that, for example,

$$
P_{\mathrm{H}}=\left(\frac{\theta}{\theta-1}\right) W=\mathcal{E} P_{\mathrm{H}}^{*} .
$$

In particular, allowing international price discrimination would not affect the results in this model.

The relative price of imports moves with the exchange rate, however, so both the real exchange and the terms of trade can still vary. Observe that

$$
\begin{gathered}
\text { real exchange rate } \equiv \frac{\mathcal{E} P^{*}}{P}=\frac{\mathcal{E} P_{\mathrm{T}}^{* \gamma} P_{\mathrm{N}}^{*(1-\gamma)}}{P_{\mathrm{T}}^{\gamma} P_{\mathrm{N}}^{(1-\gamma)}}=\left(\frac{\mathcal{E} W^{*}}{W}\right)^{1-\gamma} \\
\text { terms of trade } \equiv \frac{\mathcal{E} P_{\mathrm{F}}^{*}}{P_{\mathrm{H}}}=\frac{\mathcal{E} W^{*}}{W}
\end{gathered}
$$

\subsection{Output market clearing}

Because of unit demand elasticities and the budget constraints $P_{\mathrm{T}} C_{\mathrm{T}}=P_{\mathrm{H}} Y_{\mathrm{H}}$ and $\mathcal{E} P_{\mathrm{T}}^{*} C_{\mathrm{T}}^{*}=P_{\mathrm{T}} C_{\mathrm{T}}^{*}=P_{\mathrm{F}} Y_{\mathrm{F}}$, one can easily show that, in all states of nature,

$$
C_{\mathrm{T}}=C_{\mathrm{T}}^{*} .
$$

Of course, only the traded goods component of consumption has to be equal across countries; the overall consumption indexes $C$ and $C^{*}$ need not move together. However, if we measure Home spending in units of tradables as

$$
Z \equiv C_{\mathrm{T}}+\left(\frac{P_{\mathrm{N}}}{P_{\mathrm{T}}}\right) C_{\mathrm{N}}
$$

then, because $P_{\mathrm{N}} / P_{\mathrm{T}}=(1-\gamma) C_{\mathrm{T}} / \gamma C_{\mathrm{N}}$,

$$
Z=C_{\mathrm{T}} / \gamma=C_{\mathrm{T}}^{*} / \gamma=Z^{*} .
$$


Equality of the tradables-denominated spending levels $Z$ and $Z^{*}$ will be helpful in solving the model.

For the subsequent analysis, it is important to observe that for the log consumption case $(\rho=1)$, utility is separable in tradables and nontradables. Thus, when $C_{\mathrm{T}}=C_{\mathrm{T}}^{*}$ ex post, we have perfect international sharing of consumption risks in tradable goods. When $\rho \neq 1$, however, eq. (3) implies that the marginal utility of tradables consumption depends on consumption of nontradables. Thus, $C_{\mathrm{T}}=C_{\mathrm{T}}^{*}$ no longer guarantees internationally equality of the marginal utility of tradables, as efficient risk sharing would require.

\subsection{Equilibrium preset wages and market equilibrium}

In preparation for solving the model, we now substitute the market equilibrium output and pricing conditions into the wage equations (6). Recall the budget constraint $P C=P_{\mathrm{H}} Y_{\mathrm{H}}+P_{\mathrm{N}} Y_{\mathrm{N}}=P_{\mathrm{T}} Z$ and the price markup equations of the form of eq. (7). Also, note that, due to symmetry, eq. (1) implies that in the aggregate, $L=Y_{\mathrm{H}}+Y_{\mathrm{N}}$. We thus obtain:

$$
\left(\frac{W}{W^{*}}\right)^{\frac{\nu-(1-\rho)(1-\gamma)}{2}}=\frac{\phi \theta}{(\phi-1)(\theta-1)} \frac{\mathrm{E}\left\{K \mathcal{E}^{\nu / 2} Z^{\nu}\right\}}{\mathrm{E}\left\{\mathcal{E}^{\frac{(1-\rho)(1-\gamma)}{2}} Z^{1-\rho}\right\}} .
$$

Combining eq. (11) with its Foreign analog yields:

$$
\left(\frac{W}{W^{*}}\right)^{\nu-(1-\gamma)(1-\rho)}=\frac{\mathrm{E}\left\{K \mathcal{E}^{\nu / 2} Z^{\nu}\right\} \mathrm{E}\left\{\mathcal{E}^{-\frac{(1-\rho)(1-\gamma)}{2}} Z^{1-\rho}\right\}}{\mathrm{E}\left\{K^{*} \mathcal{E}^{-\nu / 2} Z^{\nu}\right\} \mathrm{E}\left\{\mathcal{E}^{\frac{(1-\rho)(1-\gamma)}{2}} Z^{1-\rho}\right\}}
$$

Equations (11) and (12) govern the simultaneous determination of wages, expected expenditure, and the expected exchange rate.

\section{A Closed-Form Solution}

We now solve the model by assuming that the exogenous shocks $\left\{m, m^{*}, \kappa, \kappa^{*}\right\}$ are jointly normally distributed, where lower case letters denote (natural) $\operatorname{logs}$ so that, e.g., $m \equiv \log M$. We first express the wage setting equations in terms of logs and covariances of logs of the endogenous variables. Later we will write all covariances of endogenous variables in terms of the covariance matrix of exogenous productivity shocks.. 


\subsection{Expected relative wages and global spending: Quasi reduced-form solutions}

A central implication of our modeling approach is that uncertainty has an impact on the expected levels of consumption, output, and the terms of trade through its effect on ex ante wage setting. We first derive these relations.

\subsubsection{Representation of productivity disturbances in terms of "dif- ference" and "world" shocks}

Though it is not critical to our central message here, it greatly simplifies matters to assume that the Home and Foreign log productivity shocks have identical means and variances, so that $\mathrm{E} \kappa=\mathrm{E} \kappa^{*}$ and $\sigma_{\kappa}^{2}=\sigma_{\kappa^{*}}^{2}$. We can then conveniently define the "world" and "difference" productivity shocks as:

$$
\kappa_{w} \equiv \frac{\kappa+\kappa^{*}}{2}, \kappa_{d} \equiv \frac{\kappa-\kappa^{*}}{2}
$$

Note that because $\kappa$ and $\kappa^{*}$ have identical variances, $\operatorname{Cov}\left(\kappa_{w}, \kappa_{d}\right)=0$ and $\sigma_{\kappa}^{2}=\sigma_{\kappa_{w}}^{2}+\sigma_{\kappa_{d}}^{2}$. Given the linear-quadratic nature of our setup, the orthogonality of the redefined shocks will later facilitate the separate study of policy rules governing the responses to global and idiosyncratic shocks.

\subsubsection{Solutions for mean world spending and terms of trade}

Taking logs of eq. (12), we obtain

$$
\begin{gathered}
\mathrm{E} \tau \equiv \mathrm{E} e+w^{*}-w=\frac{-1}{\nu-(1-\gamma)(1-\rho)}\left\{\left[\nu^{2}-(1-\gamma)(1-\rho)^{2}\right] \sigma_{z e}\right. \\
\left.+\nu \sigma_{\kappa_{w} e}+2 \nu \sigma_{\kappa_{d} z}\right\}
\end{gathered}
$$

where $\tau$ denotes the $(\log )$ terms of trade $\mathcal{E} P_{\mathrm{F}}^{*} / P_{\mathrm{H}}$ - making the log real exchange rate $(1-\gamma) \tau$. Combining eq. (13) with eq. (11) (in log form), we solve for the expected log of consumption spending measured in tradables,

$$
\begin{aligned}
\mathrm{E} z=\frac{1}{\nu-(1-\rho)}\{\omega & +\lambda-\frac{\nu}{2[\nu-(1-\rho)]} \sigma_{\kappa}^{2}-\frac{1}{2}\left[\nu^{2}-(1-\rho)^{2}\right] \sigma_{z}^{2} \\
& \left.-\frac{1}{8}\left[\nu^{2}-(1-\gamma)^{2}(1-\rho)^{2}\right] \sigma_{e}^{2}-\nu \sigma_{\kappa_{w} z}-\frac{\nu}{2} \sigma_{\kappa_{d} e}\right\}
\end{aligned}
$$


where $\omega$ and $\lambda$ are constants that depend on the moments of $\kappa$ and $\kappa^{*}$. Recall from eq. (10) that $Z=Z^{*}$, so that $\mathrm{E} z=\mathrm{E} z^{*}$.

\subsubsection{Discussion of the expected spending and terms of trade so- lutions}

In contrast to the ad hoc linear-quadratic formulations used in standard monetary coordination models of the 1980s and 1990s (see Canzoneri and Henderson 1991), changes in the monetary policy rule affect mean wages and prices here, not only their variances. We cannot overemphasize the importance of this result. For example, eq. (13) implies that a higher covariance $\sigma_{\kappa_{w} e}$ between the world disutility of labor shock $\kappa_{w}$ and the exchange rate $e$ (a covariance that can be influenced by monetary rules) discourages planned Home labor effort (relative to Foreign's) because relative world demand for Home goods will turn out to be unexpectedly high precisely when the world marginal disutility of effort is unexpectedly high. As a consequence, Home workers will raise their preset wages (compared to Foreign's) in an attempt to reduce their relatively higher expected disutility from working.

These kind of effects are simply absent in the earlier certainty equivalent models of monetary policy coordination, but they are central to our analysis here. The potential incentives for countries to manipulate their monetary rules to raise domestic expected welfare at the expense of foreigners depend in large measure on the responses of wage setters. For example, a country can use its monetary policy rule to try to manipulate selfishly the (average values of the) real exchange rate and terms of trade.

Some of the effects in eqs. (13) and (14) are of indefinite sign and depend on the size of $\rho$, the coefficient of risk aversion. ${ }^{5}$ When $\rho=1$, a ceteris paribus rise in the variance of the log consumption measured in tradables, $\sigma_{z}^{2}$, will cause workers throughout the world to set higher wages, thereby

\footnotetext{
${ }^{4}$ Specifically,$$
\omega \equiv\left\{\log \left[\frac{(\phi-1)(\theta-1)}{\phi \theta}\right]-\mathrm{E} \kappa+\frac{(1-\rho)}{2[\nu-(1-\rho)]} \sigma_{\kappa}^{2}-\lambda\right\}
$$

$$
\lambda=\frac{(1-\rho) \gamma \nu\left[\left(1-\frac{\gamma}{2}\right) \nu-(1-\gamma)(1-\rho)\right]}{[\nu-(1-\rho)][\nu-(1-\gamma)(1-\rho)]^{2}} \sigma_{\kappa_{d}}^{2} .
$$

${ }^{5}$ See also Obstfeld and Rogoff (1998).
}

where 
feeding back into a lower value for Ez. This is also the case for $\rho<1$, but if $\rho$ is sufficiently above 1 , the effect may be reversed. The depressing effect of $\sigma_{z}^{2}$ on $\mathrm{E} z$ is declining in $\rho$. Indeed, it undergoes a sign change at $\rho=1+\nu$.

This potential sign reversal comes from the role in eqs. (11) and (12) of the random variable $Z^{1-\rho}$, which is proportional to the marginal consumption utility from lowering the wage. For $\rho<1, Z^{1-\rho}$ is a strictly concave function of $Z$, while for $\rho>1$, it is strictly convex. Since a rise in the variance of $Z$ therefore lowers $\mathrm{E}\left\{Z^{1-\rho}\right\}$ for $\rho<1$ but raises it for $\rho>1$, we see that the variance increase (all other things equal) must reduce world output and spending by more than in the $\log$ case when $\rho<1$, but by less when $\rho>1$. A similar point applies to the ambiguous effect of exchange rate variance, $\sigma_{e}^{2}$, due to the presence of the random variable $\mathcal{E}^{1-\rho}$ in eqs. (11) and (12).

\subsection{Ex post spending and the ex post exchange rate}

As a final step in expressing the variances of the endogenous variables in terms of the exogenous variables, we solve the sticky wage model for

$$
\begin{gathered}
z=\frac{1}{2 \rho}\left(m+m^{*}\right)-\frac{1}{2 \rho}\left(w+w^{*}\right)-\frac{\log \chi}{\rho}-\frac{1}{\rho} \log \left(\frac{\theta}{\theta-1}\right), \\
e=\frac{m-m^{*}}{\rho(1-\gamma)+\gamma}-\frac{(1-\rho)(1-\gamma)\left(w-w^{*}\right)}{\rho(1-\gamma)+\gamma} .
\end{gathered}
$$

Because $w$ and $w^{*}$ are predetermined, eqs. (15) and (16) fully describe the effects on $z$ and $e$ of unanticipated shocks. ${ }^{6}$ Once we specify monetary rules for $m$ and $m^{*}$, we will therefore be able to present an exact reduced-form solution to the model.

\subsection{Solving explicitly for expected utility}

In studying policy rules, we will look at their welfare implications in the limiting case as $\chi \rightarrow 0$ in eq. (3). The justification is that expenditure on money services is small relative to that on other goods. [When $\rho=1$, the solution we present below is exact, even for positive $\chi$. Observe that eq. (4),

\footnotetext{
${ }^{6}$ To solve for $z$, take logs of the money Euler eq. (4) and its Foreign counterpart, assuming that $\chi=\chi^{*}$. Then average the two, applying the definitions of the price indexes, the markup equations for prices, and the equality $C=P_{\mathrm{T}} Z / P$. The exchange rate equation is derived by a similar calculation in differences.
} 
implies that, in equilibrium, $\chi C=M / P$. So in evaluating welfare, we can simply replace the term $\log C+\chi \log \frac{M}{P}$ by $(1+\chi) \log C$.]

\subsubsection{Expected utility when $\rho=1$}

When $\rho=1$, the utility derived from consumption is simply $\log (C)$ and a Home resident's expected utility (as $\chi \rightarrow 0$ ) takes the form

$$
\mathrm{E} U=\mathrm{E} z+\left(\frac{1-\gamma}{2}\right) \mathrm{E} \tau-\frac{(\phi-1)(\theta-1)}{\nu \phi \theta}
$$

Foreign expected utility is given by

$$
\mathrm{E} U^{*}=\mathrm{E} U-(1-\gamma) \mathrm{E} \tau
$$

Equations (17) and (18) show that while expected consumption measured in tradables, Ez, is a common component of Home and Foreign utility, the real exchange rate (proportional to the terms of trade) is a potential source of conflict. Utilities can be expressed exclusively in terms of $\mathrm{E} z$ and $\mathrm{E} \tau$ only in the log case; additional factors enter when $\rho \neq 1$, as we now show.

\subsubsection{Expected utility when $\rho \neq 1$}

As $\chi \rightarrow 0$ in the case $\rho \neq 1$, we evaluate expected utility by calculating ${ }^{7}$

$$
\mathrm{E}\left\{\frac{C^{1-\rho}}{1-\rho}-\frac{K}{\nu} L^{\nu}\right\}=\left[\frac{\nu \phi \theta-(1-\rho)(\phi-1)(\theta-1)}{\nu \phi \theta(1-\rho)}\right] \mathrm{E}\left\{Z^{1-\rho}\left(\frac{\mathcal{E} W^{*}}{W}\right)^{\frac{(1-\rho)(1-\gamma)}{2}}\right\}
$$

where

$$
\mathrm{E}\left\{Z^{1-\rho}\left(\frac{\mathcal{E} W^{*}}{W}\right)^{\frac{(1-\rho)(1-\gamma)}{2}}\right\}=\frac{\mathrm{E}\left\{\exp \left[(1-\rho) z+\frac{(1-\rho)(1-\gamma)}{2} \tau\right]\right\}}{1-\rho}
$$

${ }^{7}$ The wage eq. (6) as well as the equalities in the preceding footnote, show that

$$
\mathrm{E}\left\{\frac{K}{\nu} L^{\nu}\right\}=\frac{(\phi-1)(\theta-1)}{\nu \phi \theta} \mathrm{E}\left\{C^{1-\rho}\right\}
$$

Thus,

$$
\mathrm{E} U=\left[\frac{\nu \phi \theta-(1-\rho)(\phi-1)(\theta-1)}{\nu \phi \theta(1-\rho)}\right] \mathrm{E}\left\{C^{1-\rho}\right\}
$$




$$
\begin{aligned}
=\frac{1}{1-\rho} \exp \{(1 & -\rho) \mathrm{E} z+\frac{(1-\rho)(1-\gamma)}{2} \mathrm{E} \tau+\frac{(1-\rho)^{2}}{2} \sigma_{z}^{2} \\
& \left.+\frac{(1-\rho)^{2}(1-\gamma)^{2}}{8} \sigma_{e}^{2}+\frac{(1-\gamma)(1-\rho)^{2}}{2} \sigma_{z e}\right\} .
\end{aligned}
$$

The expression for Foreign expected utility, which is proportional to $\mathrm{E}\left\{C^{* 1-\rho}\right\} /(1-\rho)$, subtracts the terms $\mathrm{E} \tau$ and $\sigma_{z e}$ above rather than adding them, but otherwise is the same. Equation (19) shows that the expected terms of trade, $\mathrm{E} \tau$, provides a potential source of international conflict, just as in the $\rho=1$ case; see eq. (17). An internationally asymmetric welfare distribution might also be induced by the covariance $\sigma_{z e}$ between world demand and the exchange rate, independently of the influence that covariance exerts already through the expected terms of trade; see eq. (13).

\section{Policy Coordination: Globally Efficient Pre- commitment to Monetary Rules}

Per our discussion in the introduction, we restrict our attention to comparing policy rules, so that the monetary authorities cannot try to use inflation surprises to raise employment and output systematically from their suboptimal monopoly levels towards their competitive levels. Similarly, they cannot attempt to manipulate the terms of trade ex post through monetary surprises. Instead, before economic activity takes place, monetary authorities choose feedback rules that they are committed to obey thereafter. Under these rules, money supplies are functions of the productivity shocks $K$ and $K^{*}$, which the authorities observe and respond to after wages are set.

In sticky wage or price models with additional distortions, it need not be the case in general that optimal monetary policy aims simply to mimic the flexible-wage equilibrium. The reason is that the multiple distortions (in the present setup, including wage stickiness, monopoly, and the possible failure of international consumption risk sharing) can interact. Nevertheless, it turns out that for the particular stylized structure we have assumed, the optimal solution to the global cooperation problem indeed replicates the flexible-wage solution in a number of important cases, as we shall now demonstrate. 


\subsection{Optimal cooperation and the flex-wage allocation}

If policymakers could cooperate in choosing their domestic monetary policy rules, then with equal weights on national welfares, they would maximize

$$
\mathrm{E} V=\frac{1}{2} \mathrm{E} U^{*}+\frac{1}{2} \mathrm{E} U
$$

To accomplish this, they would maximize over the coefficients in monetary policy feedback rules of the form

$$
\begin{aligned}
\hat{m} & =-\delta_{d} \hat{\kappa}_{d}-\delta_{w} \hat{\kappa}_{w}, \\
\hat{m}^{*} & =\delta_{d}^{*} \hat{\kappa}_{d}-\delta_{w}^{*} \hat{\kappa}_{w},
\end{aligned}
$$

where carets over variables denote innovations, e.g., $\hat{m} \equiv m-\mathrm{E} m$. (Given the loglinear structure of the model, it is plausible to guess that optimal monetary rules will be loglinear too. Of course, $\mathrm{E} \kappa_{w}=\mathrm{E} \kappa=\mathrm{E} \kappa^{*}$, so $\mathrm{E} \kappa_{d}=0$.)

\subsubsection{Expected utilities under flexible and sticky wages}

As a first step in understanding cooperation and conflict in the choice of domestic policy rules, we calculate the flexible- and sticky-wage levels of utility in Home and Foreign.

Under flexible wages monetary policy is irrelevant and the level of expected utility, denoted by a tilde, is

$$
\mathrm{E} \tilde{U}=\frac{1}{\nu}\left\{\log \left[\frac{(\phi-1)(\theta-1)}{\phi \theta}\right]-\frac{(\phi-1)(\theta-1)}{\phi \theta}-\mathrm{E} \kappa\right\}=\mathrm{E} \tilde{U}^{*}
$$

when $\rho=1$, where we have imposed $\mathrm{E} \kappa=\mathrm{E} \kappa^{*}$ and $\sigma_{\kappa}^{2}=\sigma_{\kappa^{*}}^{2}$. For $\rho \neq 1$,

$$
\mathrm{E} \tilde{U}=\mathrm{E} \tilde{U}^{*}=\left[\frac{\nu \phi \theta-(1-\rho)(\phi-1)(\theta-1)}{\nu \phi \theta(1-\rho)}\right] \exp \left[\frac{(1-\rho) \omega}{\nu-(1-\rho)}\right],
$$

where the constant $\omega$ is defined in footnote 4 .

Expected Home utility under sticky wages can be written in terms of the flex-wage expected utility levels given above and the economic uncertainties

caused by wage rigidity. Using eqs. (13) and (14) to substitute for $\mathrm{E} \tau$ and $\mathrm{E} z$ in eqs. (17) and (19), one calculates that for $\rho \neq 1$

$$
\mathrm{E} U=(\mathrm{E} \tilde{U}) \exp [(1-\rho) \Omega(\rho)]
$$


where $\Omega(\rho)$ is defined (for any $\rho>0$ ) as the sum of two terms,

$$
\Omega(\rho)=\Omega_{w}(\rho)+\Omega_{d}(\rho),
$$

such that

$$
\begin{aligned}
\Omega_{w}(\rho)= & -\frac{\nu}{2[\nu-(1-\rho)]^{2}}\left(\sigma_{\kappa_{w}}^{2}+\sigma_{\kappa_{d}}^{2}\right)+\frac{\lambda}{\nu-(1-\rho)} \\
& -\frac{\nu}{2} \sigma_{z}^{2}-\frac{\left[\nu-(1-\gamma)^{2}(1-\rho)\right] \frac{\nu}{8} \sigma_{e}^{2}+\nu \sigma_{\kappa_{w} z}+\frac{\nu}{2} \sigma_{\kappa_{d} e}}{\nu-(1-\rho)}
\end{aligned}
$$

and

$$
\Omega_{d}(\rho)=-\frac{(1-\gamma)}{2}\left\{\frac{\nu[\nu-(1-\rho)] \sigma_{z e}+\nu \sigma_{\kappa_{w} e}+2 \nu \sigma_{\kappa_{d} z}}{\nu-(1-\gamma)(1-\rho)}\right\} .
$$

For $\rho=1$, the expression corresponding to eq. (25) is

$$
\mathrm{E} U=\mathrm{E} \tilde{U}+\Omega(1)
$$

For Foreign,

$$
\mathrm{E} U^{*}=(\mathrm{E} \tilde{U}) \exp \left[(1-\rho) \Omega^{*}(\rho)\right]
$$

when $\rho \neq 1$, and when $\rho=1, \mathrm{E} U=\mathrm{E} \tilde{U}+\Omega^{*}(1)$, where

$$
\Omega^{*}(\rho)=\Omega_{w}(\rho)-\Omega_{d}(\rho) .
$$

Obviously, $\Omega_{w}(\rho)$ is a symmetric component of world utility that affects Home and Foreign welfare equally. For example, a rise in the variance of world spending $\left(\sigma_{z}^{2}\right)$ or in that of the exchange rate $\left(\sigma_{e}^{2}\right)$ has symmetrical negative expected utility effects upon Home and Foreign.

The term $\Omega_{d}(\rho)$ is an asymmetric utility component that affects Home and Foreign in opposite ways. For example, a rise in $\sigma_{\kappa_{w} e}$ hurts Home because it becomes more likely that demand for Home output will be unexpectedly high when there is an unexpectedly high global aversion to effort. But that same change represents a commensurate benefit to Foreign. ${ }^{8}$

\footnotetext{
${ }^{8}$ Observe that whereas $\mathrm{E} \tilde{U}=\mathrm{E} \tilde{U}^{*}$ when $\mathrm{E} \kappa=\mathrm{E} \kappa^{*}$ and $\sigma_{\kappa}^{2}=\sigma_{\kappa^{*}}^{2}, \mathrm{E} U$ still need not equal $\mathrm{EU}^{*}$ if monetary policies are asymmetric.
} 


\subsubsection{Multiple distortions and the efficiency of the flexible-wage equilibrium}

Is it efficient (from an ex ate standpoint) to have monetary policy rules aim to mimic the flexible-wage equilibrium, as in 1980s style of rational-expectations monetary models? In general, the answer is not trivial, as we have noted, since wage stickiness is not the only distortion here. In this subsection we establish a sufficient condition under which optimal cooperative choice of the policy rules (21) and (22) results in the flexible-wage allocation ex post. ${ }^{9}$

Proposition 1 If the flexible-wage allocation is constrained Pareto efficient (subject to the constraint that labor supplies are at monopolistic levels), a global monetary policy rule that gives the same real allocation as under flexible wages is efficient.

Proof: (Sketch). There are two main elements of the proof. First, we observe that monetary policy reaction functions (21) and (22) with

$$
\begin{aligned}
& \delta_{d}^{\text {flex }}=\delta_{d}^{* \text { flex }}=\frac{\rho(1-\gamma)+\gamma}{\nu-(1-\gamma)(1-\rho)}, \\
& \delta_{w}^{f l e x}=\delta_{w}^{* \text { flex }}=\frac{\rho}{\nu-(1-\rho)},
\end{aligned}
$$

indeed replicate the flexible-wage equilibrium, so such a policy is always feasible in this model. ${ }^{10}$ Second, we note that the parameters $\theta$ and $\phi$ governing the monopoly distortion terms in (25) and (28) affect only the identical additive or multiplicative constant $\mathrm{E} \tilde{U}$, but not any of the elements of $\Omega(\rho)$. Thus one can offer subsidies to production and employment that eliminate the monopoly distortions in the goods and labor markets (in both countries) while affecting only $\mathrm{E} \tilde{U}$ but not the relevant gap between $\mathrm{E} U$ and $\mathrm{E} \tilde{U}$. With optimal subsidies in place, the flexible-wage equilibrium is clearly first-best efficient (in terms of expected utilities) under the assumption in the proposition: all distortions have been eliminated. Since the subsidies affect only E $\tilde{U}$ in (25) and (28), it therefore follows that even in their absence, one cannot Pareto-improve upon replicating the flexible-wage equilibrium ex post.

\footnotetext{
${ }^{9}$ The proposition strengthens and generalizes the log-case $(\rho=1)$ result proved in Obstfeld and Rogoff (2000).

${ }^{10}$ Verification is left to the reader. (See also appendix 2.)
} 
Under the assumptions of Proposition 1, targeting the flexible-wage allocation is also the optimal cooperative policy given the assumed 50-50 weights on country utility in the planner objective function (20). The reason is that $\mathrm{E} \tilde{U}=\mathrm{E} \tilde{U}^{*}$; see eq. (24). Later, however, we will see that Proposition 1 gives a sufficient condition for optimality regardless of the weights in (20).

\subsection{Optimal cooperation}

The proposition just proved allows a quick but partial characterization of optimal policies. When all productivity shocks are world shocks (that is, $\hat{\kappa}_{d} \equiv 0$ ), or when $\rho=1$, the sharing of tradable consumption risks is efficient and there is no global distortion to the flexible-wage equilibrium other than the ones caused by monopoly (which enter separably). In these latter cases, therefore, we would expect optimal cooperative policies to target the flexwage allocation. More generally, however, international risk sharing may not be efficient and economic distortions (other than our particular specification of monopoly power) may interact with the sticky-wage distortion to dictate ex post deviations from the flexible-wage allocation. ${ }^{11}$

To better understand the general case, we now solve explicitly for the efficient policy rules.

\subsubsection{The cooperative objective function}

Equations (17), (18), and (20) show that when $\rho=1$, the objective to be maximized through policy cooperation is simply

$$
\mathrm{E} V=\frac{1}{2} \mathrm{E} U^{*}+\frac{1}{2} \mathrm{E} U=\mathrm{E} z+\text { constant. }
$$

When $\rho \neq 1$, expected utility is given for the two countries by eq. (19) and its Foreign analog. Differentiating eq. (20) with respect to any policyrule parameter $\delta$, and noting that $\mathrm{E}\left\{C^{1-\rho}\right\}=\mathrm{E}\left\{C^{* 1-\rho}\right\}$ in a symmetric equilibrium, the planner's first order conditions can be written as

$$
\frac{\mathrm{d}\left\{\mathrm{E} z+\frac{(1-\rho)}{2} \sigma_{z}^{2}+\frac{(1-\rho)(1-\gamma)^{2}}{8} \sigma_{e}^{2}\right\}}{\mathrm{d} \delta}=0 .
$$

\footnotetext{
${ }^{11}$ The statement assumes that $0<\gamma<1$, so that there are some nontradable goods $(\gamma<1)$ and also some tradable consumption risks to be shared $(\gamma>0)$.
} 
By this logic, we see that for any value of $\rho$, one can derive the optimal cooperative monetary policy rules by assuming that policymakers seek

$$
\begin{aligned}
\max \mathrm{E} V & =\max \left\{\mathrm{E} z+\frac{(1-\rho)}{2} \sigma_{z}^{2}+\frac{(1-\rho)(1-\gamma)^{2}}{8} \sigma_{e}^{2}\right\} \\
& =\max \left\{\frac{\omega}{\nu-(1-\rho)}+\Omega_{w}(\rho)\right\}
\end{aligned}
$$

over the parameters in their linear monetary policy feedback rules. (Recall again that $\omega$ is the constant defined in footnote 4.)

The two countries place opposite weights on the expected real exchange rate and on the covariance $\sigma_{z e}$ between world spending and the exchange rate. These two factors thus disappear at the global level. This need not imply, of course, that monetary authorities try to fix the nominal exchange rate, unless the Home and Foreign productivity shocks happen to be perfectly correlated.

\subsubsection{Cooperative solution}

To find the cooperative monetary policy, which maximizes (32), we need to consider ex post values of $z$ and $e$ so as to calculate the covariances in $\Omega_{w}(\rho)$ as functions of the monetary policy parameters; recall eq. (26). Expressions (15) and (16) show that rules having the form of (21) and (22) imply

$$
\begin{gathered}
\hat{z}=-\left(\frac{\delta_{d}-\delta_{d}^{*}}{2 \rho}\right) \hat{\kappa}_{d}-\left(\frac{\delta_{w}+\delta_{w}^{*}}{2 \rho}\right) \hat{\kappa}_{w}, \\
\hat{e}=-\left[\frac{\delta_{d}+\delta_{d}^{*}}{\rho(1-\gamma)+\gamma}\right] \hat{\kappa}_{d}-\left[\frac{\delta_{w}-\delta_{w}^{*}}{\rho(1-\gamma)+\gamma}\right] \hat{\kappa}_{w} .
\end{gathered}
$$

Appendix 1 uses these expressions to write the covariances in $\Omega_{w}(\rho)$ in terms of the $\delta$ policy parameters.

The next step is to solve the four first-order conditions given by eq. (31) for the cooperatively optimal parameters $\delta_{d}^{c o o p}, \delta_{d}^{* \operatorname{coop} p}, \delta_{w}^{c o o p}$, and $\delta_{w}^{* c o o p}$. By symmetry, $\delta_{d}^{c o o p}=\delta_{d}^{* \text { coop }}$ and $\delta_{w}^{c o o p}=\delta_{w}^{* c o o p}$, where (again, see appendix 1)

$$
\begin{aligned}
\delta_{d}^{c o o p} & =\frac{\rho(1-\gamma)+\gamma}{\nu-(1-\gamma)^{2}(1-\rho)} \\
\delta_{w}^{c o o p} & =\frac{\rho}{\nu-(1-\rho)}
\end{aligned}
$$


Observe that due to the symmetry of the model, purely symmetric shocks can be handled by adjustments in world spending $z$ alone, whereas purely idiosyncratic shocks can be handled by adjustments of the exchange rate $e$ alone. The rule above represents an optimal symmetrical tradeoff between stabilization - a more aggressive procyclical response to the productivity shocks raises world utility - and variability in world spending and the exchange rate, both of which lower world utility, see (26), and are greater the more procyclical are the monetary policy rules.

Comparing the globally optimal rules in eqs. (33) and (34) with the ones that achieve the flexible-wage allocation, eqs. (29) and (30), we see first that when $\rho=1$, it is always optimal to target the flexible-wage equilibrium. That result is expected in light of Proposition 1.

Generalizing to values of $\rho$ other than 1 , it remains true that $\delta_{w}^{c o o p}=$ $\delta_{w}^{\text {flex }}$ - that is, in response to a symmetric, global productivity shock, globally optimal policy rules should seek to return the world economy to its flex-wage equilibrium. However, $\delta_{d}^{c o o p}=\delta_{d}^{\text {flex }}$ when $\rho \neq 1$ only in two polar situationswhen $\gamma=0$ and $\gamma=1$.

Proposition 1 no longer applies in general when $\rho \neq 1$ because, as we have already observed, consumption of nontradables then will affect the marginal utility of tradable goods consumption, possibly rendering inefficient the international pooling of risks to tradable goods consumption. In the special case where all shocks to productivity are global, however, risk sharing is efficient, provided that national monetary authorities also react symmetrically. Proposition 1 would still apply then, which explains why $\delta_{w}^{\text {coop }}=\delta_{w}^{\text {flex }}$.

The same logic explains why $\delta_{d}^{\text {coop }}=\delta_{d}^{\text {flex }}$ when $\gamma=0$ or 1 . In those extreme cases, either all goods are tradable (in which case international consumption risk sharing is perfect) or there are no tradables (in which case there are no consumption risks that countries can share). Thus, the reasoning in Proposition 1 applies once more.

When $\rho \neq 1$ but $0<\gamma<1$, though, the cooperative equilibrium reflects the general principle of the second-best, according to which it could be desirable to refrain from eliminating the sticky-wage distortion in order to mitigate the risk-sharing distortion. In such cases, according to eqs. (29) and $(33), \delta_{d}^{\text {coop }}<\delta_{d}^{\text {flex }}$ when $\rho<1$ but $\delta_{d}^{\text {coop }}>\delta_{d}^{\text {flex }}$ when $\rho>1$. Thus, for $\rho<1$, exchange-rate fluctuations are dampened relative to a flexible-wage rule, but they are relatively accentuated when $\rho>1$.

To understand the difference between $\delta_{d}^{\text {coop }}$ and $\delta_{d}^{\text {flex }}$ when risk sharing in tradables is imperfect, note first that by eq. (19), one can write countries' 
ex post marginal utilities of tradables as

$$
\begin{aligned}
\text { Home marginal utility of tradables } & =Z^{-\rho}\left(\frac{\mathcal{E} W^{*}}{W}\right)^{\frac{(1-\rho)(1-\gamma)}{2}}, \\
\text { Foreign marginal utility of tradables } & =Z^{-\rho}\left(\frac{\mathcal{E} W^{*}}{W}\right)^{\frac{-(1-\rho)(1-\gamma)}{2}} .
\end{aligned}
$$

Thus, ex post international marginal utility gaps result exclusively from exchange rate movements (which affect national outputs of nontradables differentially). When there is a positive shock to $\kappa_{d}$, a fall in $\mathcal{E}$ (a Home currency appreciation and a Foreign depreciation) is required to replicate the flexiblewage equilibrium. In the case $\rho<1$, Home's marginal utility of tradables is consequently below Foreign's at the flexible-wage allocation, as the preceding equations show. In a world of complete asset markets, Home would make a payment of tradables to Foreign in such states of nature. That is impossible here. However, a reduction in the extent to which $\mathcal{E}$ falls works very much like a transfer of tradables because, as a result, Home residents work harder and produce more of their traded products, Foreign residents work less and produce fewer of their traded products, and more Foreign goods are shipped to Home in exchange for fewer Home goods.

The logic is symmetric for $\rho>1$. In that case, were asset markets complete, a positive $\kappa_{d}$ would call for a transfer of tradables from Foreign to Home at the flex-wage allocation. Instead, the cooperative equilibrium calls for a sharper fall in $\mathcal{E}$ than does the flex-wage equilibrium. This induces Home residents to produce fewer of their exports and Foreign residents more of theirs than under flexible wages. ${ }^{12}$

\section{Noncooperative Choice of Policy Rules}

In designing their monetary rules and institutions, countries seldom ask what impact domestic institutional changes will have on welfare abroad. Since, as we have seen, monetary rules can affect the expected real exchange rate - and the expected real exchange rate affects ex ante welfare - recall eqs. (17) and

\footnotetext{
${ }^{12}$ Notice that when $\rho>1$, the ex post international gap in the marginal utility of tradables actually is larger at the cooperative equilibrium than at the flex-wage equilibrium. However, the marginal cost of moving further from the flex-wage equilibrium is also higher. Thus, on balance, there is no net expected gain from further increasing the coefficient $\delta_{d}^{c o o p}$.
} 
(19) - the question naturally arises as to whether an environment in which nations cooperate in setting rules might lead to a much superior outcome. Can the rules needed to achieve the cooperative equilibrium ever be implemented without a binding global monetary compact?

Having paid the setup costs of laying out our model in detail, we find it relatively easy to answer this question. We show in this section that when the optimal cooperative policy rules target the flexible-wage equilibrium ex post, those rules are also Nash equilibrium rules. Remarkably, the same rules that maximize global welfare then also maximize the individual welfare of Home and Foreign. When the best cooperative rules do not mimic the flexible-wage equilibrium, however, they are not Nash equilibrium rules in our model. A corollary of this result is that countries' responses to global, internationally symmetric, shocks do not raise problems of coordination; only asymmetric shocks may be problematic.

\subsection{Nash equilibrium in policy rules}

Differentiation of eq. (19) for $\mathrm{E} U$ shows that in the Nash case, the first-order conditions for Home's problem are the same as those for the problem

$$
\max _{\delta_{d}, \delta_{w}} \underbrace{\mathrm{E} z+\frac{(1-\rho)}{2} \sigma_{z}^{2}+\frac{(1-\rho)(1-\gamma)^{2}}{8} \sigma_{e}^{2}}_{\text {global component }}+\underbrace{\frac{(1-\gamma)}{2} \mathrm{E} \tau+\frac{(1-\gamma)(1-\rho)}{2} \sigma_{z e}}_{\text {country-specific component }}
$$

given $\delta_{d}^{*}$ and $\delta_{w}^{*}$. Foreign's effective objective function is simply the global component above less the country-specific component. ${ }^{13}$ In terms of our notation in eqs. (26) and (27), we can pose Home's problem equivalently as

$$
\max _{\delta_{d}, \delta_{w}} \underbrace{\frac{\omega}{\nu-(1-\rho)}+\Omega_{w}(\rho)}_{\text {global component }}+\underbrace{\Omega_{d}(\rho)}_{\text {country-specific component }} .
$$

\footnotetext{
${ }^{13}$ Observe that Home's "effective" objective function, given immediately above, can be expressed as

$$
\log \mathrm{E}\left\{Z\left(\frac{\mathcal{E} W^{*}}{W}\right)^{\frac{1-\gamma}{2}}\right\}-\frac{\rho}{2} \operatorname{Var}\left\{z+\frac{(1-\gamma)}{2} \tau\right\}
$$

that is, as the log of expected real consumption, $\mathrm{E} C$, less a risk premium proportional to the coefficient of risk aversion $\rho$ and the variance of log real consumption.
} 
Starting at the cooperative equilibrium, a small move of $\delta_{d}^{* \text { coop }}$ away from $\delta_{d}^{c o o p}$, say, has no first-order impact on the global component of Home expected utility because that term is maximized by a global planner; recall eq. (31). Yet, given the Foreign policy rule, Home might still wish to change its own rule, reaping a net domestic gain by shifting the utility-relevant terms $\mathrm{E} \tau$ and $\sigma_{z e}$ in its favor while lowering the global component of welfare by less. In that case, of course, Foreign would lose more than Home gains, and, starting at the cooperative equilibrium, Foreign would face a symmetrical incentive to make a "beggar-thy-neighbor" change in its policy rule.

The Nash equilibrium, like the cooperative one, is symmetric, so $\delta_{d}^{\text {Nash }}=$ $\delta_{d}^{* N a s h}$ and $\delta_{w}^{\text {Nash }}=\delta_{w}^{* N a s h}$. Going beyond this observation, our next result tells us that there is no individual incentive for countries to defect from the cooperative equilibrium when that equilibrium mimics the flexible-wage equilibrium ex post.

Proposition 2 In the Nash monetary policy rule setting equilibrium, $\delta_{d}^{\text {Nash }}=$ $\delta_{d}^{\text {coop }}=\delta_{d}^{\text {flex }}$ when $\rho=1$, and $\delta_{w}^{\text {Nash }}=\delta_{w}^{\text {coop }}=\delta_{w}^{\text {flex }}$ for any $\rho>0$.

Proof. See appendix 1, where it is shown by direct calculation that

$$
\begin{gathered}
\delta_{d}^{N a s h}=[\rho(1-\gamma)+\gamma]\left\{\frac{1+(1-\gamma) \frac{\delta_{d}^{f l e x}}{\delta_{w}^{f l e x}}}{\left[\nu-(1-\gamma)^{2}(1-\rho)\right]+(1-\gamma)[\nu-(1-\rho)] \frac{f_{d}^{\text {flex }}}{\delta_{w}^{\text {flex }}}}\right\}, \\
\delta_{w}^{\text {Nash }}=\frac{\rho}{\nu-(1-\rho)} .
\end{gathered}
$$

Setting $\rho=1$ in eq. (36) and comparing the result with eqs. (33) and (29) for $\rho=1$ proves the first part of the proposition, while comparison of eq. (37) with eqs. (34) and (30) establishes the second part.

Proposition 2 shows that when the flexible-wage equilibrium is constrainedefficient with respect to the monopoly distortions, Home doesn't gain by unilaterally moving its policy rule away from cooperation. Constrained efficiency always holds when $\rho=1$, and it holds for any $\rho>0$ when all shocks are symmetric. Thus the cooperative equilibrium - when it mimics the flexiblewage equilibrium - is also the Nash equilibrium of the rule-setting game. But notice that our result actually is stronger than this. In fact, the proposition states that Home never gains from changing its response to symmetric shocks 
even when asymmetric shocks can occur and $\rho \neq 1$. This "separability" property follows from the basic linear-quadratic nature of our model, coupled with the orthogonality of the "world" and "difference" shocks.

Regarding the Nash response to idiosyncratic shocks, we have

Proposition 3 In the Nash monetary policy rule setting equilibrium, $\delta_{d}^{\text {flex }}>$ $\delta_{d}^{\text {Nash }}>\delta_{d}^{\text {coop }}$ when $\rho<1$ and $\delta_{d}^{\text {flex }}<\delta_{d}^{\text {Nash }}<\delta_{d}^{\text {coop }}$ when $\rho>1$.

Proof. Left to the reader.

The proof of Proposition 2 in appendix 1 confirms our earlier claim that under the assumptions of Proposition 1, it is optimal for a global planner to target the flexible-wage equilibrium regardless of the country welfare weights in the objective function (20). Thus, we have:

Corollary 4 If the flexible-wage allocation is constrained Pareto efficient, a global monetary policy that gives the same real allocation as under flexible wages is optimal even for a supranational planner who favors one country over the other.

\subsection{Discussion of Propositions 2 and 3}

Proposition 2 reports the Nash response to asymmetric shocks, and Proposition 3 shows that it lies between the cooperative and flexible-wage response coefficients. When $\rho<1$, countries respond more aggressively to idiosyncratic shocks than is globally efficient - and as a result, exchange rate variability is excessive relative to the benchmark of optimal cooperation. When $\rho>1$, however (more likely the relevant case empirically), the Nash equilibrium actually produces more stable exchange rates than does cooperation.

Why? The covariance $\sigma_{z e}$ is bigger the more activist is Home's monetary policy. As equation (27) shows, this has a negative effect on Home. High $\sigma_{z e}$ implies that world demand is high precisely when the exchange rate is shifting demand toward Home workers. At relatively high values of $\rho$, the domestically beneficial reduction in $\sigma_{z e}$ due to reduced monetary activism dominates the domestic harm due to the concomitant rise in $\sigma_{\kappa_{d} z}$, implying that, left to its own devices, Home would choose a monetary rule that stabilizes the exchange rate more than under cooperation.

By changing its rule to reduce $\sigma_{z e}$, Home inflicts a direct beggar-thyneighbor loss on Foreign, of course. But at the same time $\Omega_{w}(\rho)$ (a shared, 
global component of welfare) declines because $\sigma_{\kappa_{d}}$ rises; see eq. (26). This last effect hurts both countries, which have a common interest in seeing the Home currency relatively appreciated (and the Foreign currency, therefore, relatively depreciated) when Home productivity is relatively high (and, therefore, Foreign productivity relatively low).

While the result of Proposition 3 is not surprising in view of the type of coordination failure stressed in the earlier policy cooperation literature, Proposition 2's conclusion that the Nash and cooperative equilibria of the rule-setting game can coincide contrasts sharply with that literature. After all, much of the older coordination literature dealt with the consequences of noncooperative (ex post) responses to common (that is, symmetric) shocks. Here, the response to such common shocks resulting from cooperative choice of rules always is the same as that resulting from noncooperative choice (and the responses to any shocks are the same when $\rho=1$ ). In our setting, the need for a global monetary authority to ensure that countries pay attention to spillovers when they establish monetary rules certainly diminishes. Why?

The basic reason for Proposition 2 is that these are cases in which the policy rule is designed to mimic the constrained-efficient flexible-wage equilibrium, thus setting to zero the Home and Foreign sticky-wage distortions measured by ${ }^{14}$

$$
\Omega(\rho)=\Omega_{w}(\rho)+\Omega_{d}(\rho)
$$

and

$$
\Omega^{*}(\rho)=\Omega_{w}(\rho)-\Omega_{d}(\rho) .
$$

But if the sticky-wage distortion has been eliminated, a small increase in the distortion through a change in the policy rule has no first-order welfare effect on Home or Foreign. ${ }^{15}$ That is, when the policy parameter $\delta$ that solves

$$
\frac{\mathrm{d} \Omega_{w}(\rho)}{\mathrm{d} \delta}=0
$$

\footnotetext{
${ }^{14}$ Of course these terms are not necessarily zero when $\rho \neq 1$ and asymmetric shocks can occur. Indeed, it can be shown (after much algebra) that under the cooperative regime,

$$
\Omega(\rho)=\frac{\nu \gamma^{2}(1-\gamma)^{2}(1-\rho)^{2} \sigma_{\kappa_{d}}^{2}}{2[\nu-(1-\rho)][\nu-(1-\gamma)(1-\rho)]^{2}\left[\nu-(1-\gamma)^{2}(1-\rho)\right]}>0 .
$$

However, $\delta_{w}$ and $\delta_{d}$ enter $\Omega(\rho)$ separably, so we can analyze the problem of choosing $\delta_{w}$ as if asymmetric shocks were absent altogether.

${ }^{15}$ It is critical to this argument that the monopoly distortions have effects that are completely separable from those of the sticky-wage distortion, as we have shown above.
} 
leads to the flexible-wage equilibrium ex post, it must also be true that

$$
\frac{\mathrm{d} \Omega(\rho)}{\mathrm{d} \delta}=\frac{\mathrm{d} \Omega^{*}(\rho)}{\mathrm{d} \delta}=\frac{\mathrm{d} \Omega_{d}(\rho)}{\mathrm{d} \delta}=0 .
$$

Thus, neither country will be tempted to deviate from any policy rule parameter which, taken individually, is tailored to eliminate the effects of sticky wages on the economy's allocation. ${ }^{16}$

Implicit in the preceding discussion is the presumption that the sticky wage lowers national welfare because wage setters would always prefer to have the option of resetting their wages after uncertainty is realized: when there are no asymmetric shocks (or when $\rho=1$ ), $\Omega(\rho)$ is maximized at a value of 0 . But while sticky wages clearly lower individual welfare, might one not argue that they somehow could coordinate workers on an outcome more favorable to national welfare than the flexible-wage equilibrium? This cannot occur through the micro-level monopoly channel, as we have seen, since uncertainty does not interact with the monopoly distortion in our model. But it could, conceivably, occur through a separate, macro-level, channel. As a general matter, the decisions of individual wage setters need not completely internalize a country's monopoly power over its exports; see Obstfeld and Rogoff (1998, appendix D.2) and Tille (2000). Indeed, in the present model, individual domestic producers overestimate the global elasticity of demand for their products, so that either country could raise its own welfare, at the other's expense, by imposing an optimal import tariff. Might not a monetary policy rule be designed likewise to exploit a country's monopoly power in trade, thereby, perhaps, raising $\Omega(\rho)$ above zero even in the absence of a risk-sharing distortion?

The answer is no, essentially for the same reason that the sticky-wage distortion does not interact with the micro-level monopoly distortion. To see this, imagine that Home imposes an optimal import tariff to exploit its national monopoly power in trade. Appendix 2 shows that in the flex-wage equilibrium with an ad valorem tariff of $t$, Home's utility $\tilde{U}(t)$ has the form

$$
\tilde{U}(t)=\Psi(t) \tilde{U}(0)=\Psi(t) \tilde{U}
$$

implying that the optimal tariff is state-independent. Hence the optimal

\footnotetext{
${ }^{16}$ In the logarithmic case $(\rho=1)$, we infer that a small shift in the policy rule does not induce any change in the nominal wages that workers choose ex ante. When $\rho \neq 1$, however, wages do change.
} 
tariff under uncertainty maximizes

$$
\Psi(t) \mathrm{E} U=\Psi(t)(\mathrm{E} \tilde{U}) \exp [(1-\rho) \Omega(\rho)] .
$$

But the first-order condition for the nationalistically optimal tariff $\left(\Psi^{\prime}(t)=\right.$ $0)$ is independent from the conditions for optimal nationalistic monetary policy $[\mathrm{d} \Omega(\rho) / \mathrm{d} \delta=0]$. Thus, Home's ex ante welfare is maximized when the allocational effects of sticky wages are nullified ex post by monetary policy, irrespective of whether the optimal Home tariff is actually in place.

\subsection{Can one plausibly generate big coordination gains?}

One way to assess the quantitative importance of the gain from coordination when $\rho \neq 1$ and $\sigma_{\kappa_{d}}^{2}>0$ is to simulate our model numerically. To that end, we assume $\sigma_{\kappa_{d}}^{2}=\sigma_{\kappa_{w}}^{2}=.01$, that $\gamma=0.6$, and that $\nu=1.5$ (the value used by Chari, Kehoe, and McGrattan 1998). For different values of $\rho$, table 1 calculates three numbers: (i) the gain from monetary policies that target the flexible-wage equilibrium, compared with policies that hold money supplies constant; (ii) the gain from moving from flex-wage policies to the cooperative equilibrium; and (iii) the ratio of (ii) to (i). The gains (i) and (ii) are expressed as percentages of output. Notice that because the Nash equilibrium policy responses lie between the flex-wage and cooperative responses, the ratio (iii) is a strict upper bound on the gains to cooperative versus Nash behavior in rule setting.

Table 1: Gains from stabilization and coordination

\begin{tabular}{lccccc}
\hline Measure & $\rho=0.5$ & $\rho=1$ & $\rho=2$ & $\rho=4$ & $\rho=8$ \\
\hline (i) Stabilization gain & 1.28 & 0.67 & 0.30 & 0.12 & 0.04 \\
(ii) Coordination gain & $4.5 \times 10^{-3}$ & 0 & $2.9 \times 10^{-3}$ & $6.0 \times 10^{-3}$ & $5.1 \times 10^{-3}$ \\
(iii) Ratio (ii)/(i) & $3.5 \times 10^{-3}$ & 0 & $9.7 \times 10^{-3}$ & 0.05 & 0.13 \\
\hline
\end{tabular}

The gain to stabilization falls sharply with $\rho$ because the higher is $\rho$, the less the necessary adjustment of wages to productivity shocks in the flexiblewage equilibrium (see appendix 2). However, the net gain to cooperation versus simply targeting the flex-wage allocation is uniformly tiny. Only at unrealistically high values of $\rho$, at which the gain to stabilization is very small, does the gain from coordination climb to even a tenth of the gain 
from stabilization. Thus, the discrepancy between the Nash and cooperative equilibria seems truly negligible in welfare terms, even when measured against a limited scope for stabilization.

Our results here are consistent with a much broader literature which finds that at the aggregate national level, the potential utility gains from increased international risk sharing are not necessarily large (see Obstfeld and Rogoff 1996), especially in a setting such as the present one where price effects already provide a significant measure of risk sharing.

\subsection{Discussion}

How general are our results? We may easily dispatch three potential criticisms. First, our analysis extends to the case where real balances enter utility in the form $(M / P)^{1-\varepsilon} /(1-\varepsilon)$, as in Obstfeld and Rogoff (2000). Though the formulas are more complicated than in the present paper's $\varepsilon=1$ case, the main results all go through and the intuition is the same.

Second, one can show that our main result does not rely on the monetary authorities being able to observe productivity shocks exactly or hit the flexwage allocation exactly. What is central is that policymakers be using their information efficiently in their efforts to stabilize.

Third, our model assumes that only wages are sticky and that product prices are flexible at the consumer level. This, too, need not be important. One can carry out our analysis in a model where all consumer prices, of both domestic and imported goods, are preset in domestic currency terms, and our main result that the scope for policy coordination is limited still follows.

Clearly, however, the specific log-linear form of the model is critical to the exact analytical results we have obtained. Especially important for our results is the convenient but not necessarily realistic assumption of unitary international demand elasticities, which leads to the equality (10). We conjecture that our model, augmented with complete international asset markets, would admit no gains whatsoever from coordinated rule setting even with general demand elasticities. Whether reasonable nonlinearities would result in quantitatively important gains from ex ante coordination under incomplete asset markets is a subject for future research. Our numerical investigation of the gains from coordination when $\rho \neq 1$ suggests the gains may be small. 


\section{Comparisons with Earlier Literature}

Perhaps the paper whose message is most closely related to ours is Oudiz and Sachs (1984), who also argue that the benefits to international policy coordination may be very small, though for very different reasons. Their empirical model of coordination between the United States and Europe yields small gains only because trade between the two regions is small. Our result, in contrast, holds just as strongly when the two regions are highly integrated. There are other fundamental differences, not least that Oudiz and Sachs study ex post coordination rather than a rule-setting game, and that they use an old-fashioned Keynesian trade multiplier model. Also, as in all the previous literature, their model is one in which monetary policy cannot systematically raise the expected value of output or employment whereas here it can (via agents' responses to risk). ${ }^{17}$

Our paper does not actually explore the institutional mechanisms by which a rule-based regime might be implemented. Interesting recent work by Jensen (2000), which builds on earlier results by Persson and Tabellini (1995) and Rogoff (1985), shows that it may indeed be possible to implement institutions at the national level that could mitigate the credibility problems of national monetary authorities both vis-à-vis wage setters and vis-à-vis each other. The question our paper answers is whether, in designing such institutions, countries have any incentives to pay attention to the international spillover effects, even if a mechanism for doing so exists. Persson and Tabellini (1995) do, in fact, informally consider whether the globally optimal cooperative contracting scheme could be the outcome of a game in which countries set contracts unilaterally. They argue that, under some conditions, it could (even if other equilibria are possible also). Persson and Tabellini also note, however, that their contracting scheme may be rather fragile, a point Drazen (2000) emphasizes. What our result shows is that elaborate mechanisms for reaching a cooperative equilibrium in monetary policy may be entirely unnecessary.

\footnotetext{
${ }^{17}$ Unlike earlier cooperation papers, we do not include an ad hoc inflation term in the monetary authorities' objective functions. Though it is a perhaps only a sleight of hand, we could have done so by assuming overlapping Calvo (1983) contracts, while taking the initial level of wages as given. Then, of course, any change in the monetary rule has (by definition) a surprise element to it (due to the preexisting wage contracts), and therefore the level of inflation has a redistributive effect. (See Woodford 1999.) Our analysis neglects these transitional issues.
} 
If there were no way to design domestic institutions to effectively enforce policy rules, then international monetary policy credibility problems could easily arise in our model. There are two wedges, one inflationary and one deflationary. The monopoly distortions in the goods and labor markets could be mitigated if the monetary authorities could systematically inflate beyond wage setters' expectations. On the other hand, there is also a systematic incentive to try to deflate and thereby lower domestic output for optimal tariff reasons. Corsetti and Pesenti (2000) give some suggestive results for this ex post monetary policy game, though their model is not stochastic so they cannot analyze monetary policy rules. ${ }^{18}$

\section{Conclusions}

As the major currency countries adopt institutions more conducive to rulebased monetary policy, one might be concerned that they seem to be so inward-looking in their decision-making processes. Modern models of monetary policy transmission suggest a number of channels that might lead countries to choose monetary rules that are optimal from a national perspective but not from a global perspective. While in principle this problem perhaps can be addressed with properly designed domestic monetary institutions - as Jensen (2000) and Persson and Tabellini (1995, 2000) have suggested - in practice, spillover effects appear to receive only minimal consideration.

We have shown that, surprisingly, this lack of coordination may not be a first-order problem. As domestic monetary rules improve, and as international asset markets become more complete, the outcome of a Nash monetary rule-setting game begins to approximate the outcome of a cooperative one. In principle, the current system of monetary arrangements may evolve to one that is (nearly) optimal from a stabilization point of view, without any major institutional innovations at the international level. This answer falls remarkably neatly out of a welfare-based "new open economy macroeconomics model." Indeed, one simply cannot properly pose the question within the older Mundell-Fleming-Dornbusch style of model that, until now, has served as the workhorse of the cooperation literature.

\footnotetext{
${ }^{18}$ Corsetti and Pesenti (2000) derive the first-order conditions of a Nash equilibrium at given wages, but one cannot really explore time-consistent equilibria in their model without adding an ad hoc inflation objective or introducing repeated game considerations. They present their analysis as suggestive and do not attempt to solve fully for Nash equilibrium.
} 
Finally, we note that in our model, as in earlier stabilization models of international monetary policy, it is never optimal to have a fixed exchange rate regime unless shocks are perfectly positively correlated across countries. ${ }^{19}$ We hardly regard the analysis here as a decisive blow against having a world money, since our framework omits many potentially important elements such as excess volatility, protectionism, and the costs of making and keeping track of payments in multiple currencies. The analysis does cast some doubt, however, on halfway measures to coordinate world monetary policy such as McKinnon's (1984) "world money" targeting, or Williamson's (1985) exchange-rate target zones. Continued improvements of monetary policy institutions at the domestic level, coupled with the further broadening of world capital markets, may render such schemes superfluous or even counterproductive.

\footnotetext{
${ }^{19}$ In an interesting recent paper, Devereux and Engel (2000) develop an example in which exchange rate flexibility is not beneficial even in the face of country-specific real shocks. Exchange rate adjustment plays no short-run allocative role in their model, however, because prices of foreign goods are pre-set in local currency terms at both the importer and the consumer level. Elsewhere (Obstfeld and Rogoff 2000), we have shown that such a model has the counterfactual implication that a depreciation actually improves a country's terms of trade, rather than worsens them. Nevertheless, the question of how sticky consumer prices may affect the allocational role of the exchange rate is clearly an important one for future research.
} 


\section{References}

[1] Bergin, P., and R. Feenstra. (2000). Pricing-to-market, staggered contracts, and real exchange rate persistence. Journal of International Economics 51, forthcoming.

[2] Calvo, G. (1983). Staggered prices in a utility-maximizing framework. Journal of Monetary Economics 12: 983-998.

[3] Canzoneri, M., and D. Henderson. (1991). Monetary policy in interdependent economies. Cambridge, MA: MIT Press.

[4] Chari, V., P. Kehoe, and E. McGrattan. (1998). Monetary shocks and real exchange rates in sticky price models of international business cycles. Federal Reserve Bank of Minneapolis Research Department Staff Report No. 223.

[5] Cole, H., and M. Obstfeld. (1991). Commodity trade and international risk sharing: How much do financial markets matter? Journal of Monetary Economics 28 (August): 3-24.

[6] Corsetti, G., and P. Pesenti. (2000). Welfare and macroeconomic interdependence. Quarterly Journal of Economics, forthcoming.

[7] Devereux, M., and C. Engel. (2000). Monetary policy in the open economy revisited: Price setting rules and exchange rate flexibility. Working paper 2454, Center for Economic Policy Research (May).

[8] Drazen, A. (2000). Political economy in macroeconomics. Princeton: Princeton University Press.

[9] Jensen, H. (2000). Optimal monetary policy cooperation through stateindependent contracts with targets. European Economic Review 44 (March): 517-539.

[10] McKinnon, R. (1984). An international standard for monetary stabilization. Washington, D.C.: Institute for International Economics.

[11] Obstfeld, M. and K. Rogoff. (1995). Exchange rate dynamics redux. Journal of Political Economy 103: 624-60 
[12] Obstfeld, M. and K. Rogoff. (1996). Foundations of international macroeconomics. Cambridge, MA: MIT Press.

[13] Obstfeld, M. and K. Rogoff. (1998). Risk and exchange rates. Working paper 6694, National Bureau of Economic Research.

[14] Obstfeld, M., and K. Rogoff. (2000). New directions for stochastic open economy models. Journal of International Economics 50: 117-153.

[15] Oudiz, G., and J. Sachs. (1984). Macroeconomic policy coordination among the industrial countries. Brookings Papers on Economic Activity 1: $1-64$.

[16] Persson, T., and G. Tabellini. (1995). Double-edged incentives: Institutions and policy coordination. In Handbook of international economics, vol. 3, edited by G. Grossman and K. Rogoff. Amsterdam: Elsevier.

[17] Persson, T., and G. Tabellini. (2000). Political economics: Explaining economic policy. Cambridge, MA: MIT Press.

[18] Rogoff, K. (1985). Can international monetary cooperation be counterproductive? Journal of International Economics 18: 199-217.

[19] Svensson, L. (2000). How should monetary policy be conducted in an era of price stability? Working paper 7516, National Bureau of Economic Research.

[20] Tille, C. (2000). 'Beggar-thy-neighbor' or 'beggar-thyself'? The income effect of exchange rate fluctuations. Mimeo, Federal Reserve Bank of New York

[21] Williamson, J. (1985). The exchange rate system. 2d edition. Washington, D.C.: Institute for International Economics.

[22] Woodford, M. (1999). Optimal monetary policy inertia. Working paper 7261, National Bureau of Economic Research. 


\section{Appendix 1: Cooperative and Nash Equilibria}

This appendix shows how to calculate the cooperative and Nash equilibria when monetary rules respond to productivity shocks.

\section{Cooperative equilibrium}

The paper's text showed that cooperative policymakers will seek to maximize (32) over policy rules of the form given in eqs. (21) and (22). Equations (14), for $\mathrm{E} z$, and (32) show that to calculate the cooperative equilibrium, we must express the moments $\sigma_{z}^{2}, \sigma_{e}^{2}, \sigma_{\kappa_{w} z}$, and $\sigma_{\kappa_{d} e}$, all of which affect Home and Foreign symmetrically, in terms of the policy parameters of the reaction functions (21) and (22). Making use of the relations

$$
\begin{aligned}
& \hat{z}=-\left(\frac{\delta_{d}-\delta_{d}^{*}}{2 \rho}\right) \hat{\kappa}_{d}-\left(\frac{\delta_{w}+\delta_{w}^{*}}{2 \rho}\right) \hat{\kappa}_{w}, \\
& \hat{e}=-\left[\frac{\delta_{d}+\delta_{d}^{*}}{\rho(1-\gamma)+\gamma}\right] \hat{\kappa}_{d}-\left[\frac{\delta_{w}-\delta_{w}^{*}}{\rho(1-\gamma)+\gamma}\right] \hat{\kappa}_{w},
\end{aligned}
$$

that we derived earlier, we can write:

$$
\begin{aligned}
\sigma_{z}^{2} & =\frac{\left(\delta_{d}-\delta_{d}^{*}\right)^{2}}{4 \rho^{2}} \sigma_{\kappa_{d}}^{2}+\frac{\left(\delta_{w}+\delta_{w}^{*}\right)^{2}}{4 \rho^{2}} \sigma_{\kappa_{w}}^{2}, \\
\sigma_{e}^{2} & =\left[\frac{\delta_{d}+\delta_{d}^{*}}{\rho(1-\gamma)+\gamma}\right]^{2} \sigma_{\kappa_{d}}^{2}+\left[\frac{\delta_{w}-\delta_{w}^{*}}{\rho(1-\gamma)+\gamma}\right]^{2} \sigma_{\kappa_{w}}^{2}, \\
\sigma_{\kappa_{w} z} & =-\frac{\delta_{w}+\delta_{w}^{*}}{2 \rho} \sigma_{\kappa_{w}}^{2}, \\
\sigma_{\kappa_{d} e} & =-\frac{\delta_{d}+\delta_{d}^{*}}{\rho(1-\gamma)+\gamma} \sigma_{\kappa_{d}}^{2} .
\end{aligned}
$$

Since the cooperative maximand simplifies to

$$
\mathrm{E} V=-\frac{\nu}{2} \sigma_{z}^{2}-\frac{\left\{\left[\nu-(1-\gamma)^{2}(1-\rho)\right] \frac{\nu}{8} \sigma_{e}^{2}+\nu \sigma_{\kappa_{w} z}+\frac{\nu}{2} \sigma_{\kappa_{d} e}\right\}}{\nu-(1-\rho)}+\text { constant }
$$

once we write $\mathrm{E} z$ and $\mathrm{E} \tau$ in terms of the relevant variances and covariances of endogenous variables, recall eq. (26), the first-order conditions for the reaction function parameter $\delta_{d}$ is

$$
\frac{\mathrm{dE} V}{\mathrm{~d} \delta_{d}}=\frac{\mathrm{d} \Omega_{w}(\rho)}{\mathrm{d} \delta_{d}}=0
$$




$$
=-\frac{\nu\left(\delta_{d}-\delta_{d}^{*}\right)}{4 \rho^{2}} \sigma_{\kappa_{d}}^{2}-\frac{\nu\left(\frac{\left[\nu-(1-\gamma)^{2}(1-\rho)\right]}{2[\rho(1-\gamma)+\gamma]}\right)\left(\delta_{d}+\delta_{d}^{*}\right) \sigma_{\kappa_{d}}^{2}-\nu \sigma_{\kappa_{d}}^{2}}{2[\nu-(1-\rho)][\rho(1-\gamma)+\gamma]} .
$$

(We do not write out a verification of second-order conditions, but that detail is easily filled in given the simple structure of the model.) Observe that, thanks to the model's linearity and the orthogonality of the world and difference shocks $\kappa_{d}$ and $\kappa_{w}$, the first-order conditions for the optimal Home and Foreign cooperative response elasticities to $\kappa_{d}$ do not depend on the response elasticities to $\kappa_{w}$. A further simplification results from noting that, due to the model's symmetry, we must have $\delta_{d}^{*}=\delta_{d}$ at the optimum. Thus, the preceding first-order condition implies that

$$
\delta_{d}^{\text {coop }}=\delta_{d}^{* \text { coop }}=\frac{\rho(1-\gamma)+\gamma}{\nu-(1-\gamma)^{2}(1-\rho)},
$$

which gives us eq. (33). As we have observed, this solution differs from the flexible-wage solution, eq. (29).

To find the cooperative response elasticities $\delta_{w}^{\text {coop }}$ and $\delta_{w}^{* \text { coop }}$, we calculate

$$
\begin{aligned}
\frac{\mathrm{dE} V}{\mathrm{~d} \delta_{w}} & =\frac{\mathrm{d} \Omega_{w}(\rho)}{\mathrm{d} \delta_{w}}=0 \\
& =-\frac{\nu\left(\delta_{w}+\delta_{w}^{*}\right)}{4 \rho^{2}} \sigma_{\kappa_{w}}^{2}-\frac{\nu\left(\frac{\left[\nu-(1-\gamma)^{2}(1-\rho)\right]}{2[\rho(1-\gamma)+\gamma]^{2}}\right)\left(\delta_{w}-\delta_{w}^{*}\right) \sigma_{\kappa_{w}}^{2}-\frac{\nu}{\rho} \sigma_{\kappa_{w}}^{2}}{2[\nu-(1-\rho)]} .
\end{aligned}
$$

Again invoking the symmetry of the solution, we find that

$$
\delta_{w}^{c o o p}=\delta_{w}^{* \text { coop }}=\frac{\rho}{\nu-(1-\rho)},
$$

which is eq. (34); $\delta_{w}^{\text {coop }}$ also matches the flexible-wage response in eq. (30). Nash equilibrium

In a Nash equilibrium Home's problem is to find

$$
\max _{\delta_{d}, \delta_{w}} \mathrm{E} U
$$

given $\delta_{d}^{*}$ and $\delta_{w}^{*}$. As eq. (35) shows, Home will wish to alter its cooperative policy rule if it can bring about a first-order increase in the country-specific welfare component

$$
\Omega_{d}(\rho)=\frac{(1-\gamma)}{2} \mathrm{E} \tau+\frac{(1-\gamma)(1-\rho)}{2} \sigma_{z e} .
$$


Since the benefit to Home from any first-order increase in $\Omega_{d}(\rho)$ entails an equal loss for Foreign, Foreign (of course) would lose more than Home's gain if Home were to defect from the cooperative equilibrium.

The first-order condition with respect to $\delta_{w}$ takes the form

$$
\frac{\mathrm{dE} U}{\mathrm{~d} \delta_{w}}=\frac{\mathrm{d} \Omega_{w}(\rho)}{\mathrm{d} \delta_{w}}+\frac{\mathrm{d} \Omega_{d}(\rho)}{\mathrm{d} \delta_{w}}=0
$$

The last subsection gives the derivative $\mathrm{d} \Omega_{w}(\rho) / \mathrm{d} \delta_{w}$. To calculate $\mathrm{d} \Omega_{d}(\rho) / \mathrm{d} \delta_{w}$, recall from eq. (27) that

$$
\Omega_{d}(\rho)=-\frac{(1-\gamma)}{2}\left\{\frac{\nu[\nu-(1-\rho)] \sigma_{z e}+\nu \sigma_{\kappa_{w} e}+2 \nu \sigma_{\kappa_{d} z}}{\nu-(1-\gamma)(1-\rho)}\right\},
$$

where the relevant covariances, all of which have opposite effects on Home and Foreign expected utility, are:

$$
\begin{gathered}
\sigma_{z e}=\frac{\left(\delta_{d}^{2}-\delta_{d}^{* 2}\right) \sigma_{\kappa_{d}}^{2}+\left(\delta_{w}^{2}-\delta_{w}^{* 2}\right) \sigma_{\kappa_{w}}^{2}}{2 \rho[\rho(1-\gamma)+\gamma]}, \\
\sigma_{\kappa_{w} e}=-\frac{\delta_{w}-\delta_{w}^{*}}{\rho(1-\gamma)+\gamma} \sigma_{\kappa_{w}}^{2}, \\
\sigma_{\kappa_{d} z}=-\frac{\left(\delta_{d}-\delta_{d}^{*}\right)}{2 \rho} \sigma_{\kappa_{d}}^{2} .
\end{gathered}
$$

To find the Nash equilibrium of the rule-setting game, we note first that

$$
\frac{\mathrm{d} \Omega_{d}(\rho)}{\mathrm{d} \delta_{w}} \propto-\frac{\nu-(1-\rho)}{\rho} \delta_{w}+1
$$

Since the value

$$
\delta_{w}=\frac{\rho}{\nu-(1-\rho)}
$$

sets the preceding derivative to zero while simultaneously satisfying $\mathrm{d} \Omega_{w}(\rho) / \mathrm{d} \delta_{w}=$ 0 (recall the last subsection), we have (by symmetry) that

$$
\delta_{w}^{N a s h}=\delta_{w}^{* N a s h}=\frac{\rho}{\nu-(1-\rho)}
$$

Of course, these Nash responses to the symmetric world shock also are cooperative responses and act to mimic the flexible-wage equilibrium ex post. 
On the other hand, the cooperative response coefficient $\delta_{d}^{c o o p}=\frac{\rho(1-\gamma)+\gamma}{\nu-(1-\gamma)^{2}(1-\rho)}$ does not set to zero the derivative

$$
\frac{\mathrm{d} \Omega_{d}(\rho)}{\mathrm{d} \delta_{d}}=-\frac{(1-\gamma) \nu}{2 \rho}\left\{\frac{\frac{[\nu-(1-\rho)]}{[\rho(1-\gamma)+\gamma]} \delta_{d}-1}{\nu-(1-\gamma)(1-\rho)}\right\} \sigma_{\kappa_{d}}^{2} .
$$

To find the Nash value $\delta_{d}^{\text {Nash }}$, we therefore must solve

$$
\begin{aligned}
\frac{\mathrm{dE} U}{\mathrm{~d} \delta_{d}}= & \frac{\mathrm{d} \Omega_{w}(\rho)}{\mathrm{d} \delta_{d}}+\frac{\mathrm{d} \Omega_{d}(\rho)}{\mathrm{d} \delta_{d}}=0 \\
= & -\frac{\nu\left(\delta_{d}-\delta_{d}^{*}\right)}{4 \rho^{2}} \sigma_{\kappa_{d}}^{2}-\frac{\nu\left(\frac{\left[\nu-(1-\gamma)^{2}(1-\rho)\right]}{2[\rho(1-\gamma)+\gamma]}\right)\left(\delta_{d}+\delta_{d}^{*}\right) \sigma_{\kappa_{d}}^{2}-\nu \sigma_{\kappa_{d}}^{2}}{2[\nu-(1-\rho)][\rho(1-\gamma)+\gamma]} \\
& -\frac{(1-\gamma) \nu}{2 \rho}\left\{\frac{\frac{[\nu-(1-\rho)]}{[\rho(1-\gamma)+\gamma]} \delta_{d}-1}{\nu-(1-\gamma)(1-\rho)}\right\} \sigma_{\kappa_{d}}^{2} .
\end{aligned}
$$

The Nash equilibrium is symmetric with $\delta_{d}^{\text {Nash }}=\delta_{d}^{* N a s h}$, so the preceding equation has the solution given earlier in eq. (36).

\section{Appendix 2: Flexible-Wage Equilibrium and Tariffs}

This appendix shows the effect in a flexible-wage version of the model when Home imposes a tariff on imports. The discussion has the dual purpose of illustrating how tariffs interact with other distortions, and of showing how to solve the flexible-wage model in general.

\section{Tariffs and the distribution of world spending}

If the ad valorem tariff rate is $t$ and tariff revenues are rebated to the Home public in lump-sum fashion, then the Home consumer's budget constraint is no longer $P_{\mathrm{T}} C_{\mathrm{T}}=P_{\mathrm{H}} Y_{\mathrm{H}}$; it becomes

$$
\begin{aligned}
P_{\mathrm{T}} C_{\mathrm{T}} & =P_{\mathrm{H}} Y_{\mathrm{H}}+t \mathcal{E} P_{\mathrm{F}}^{*} C_{\mathrm{F}} \\
& =P_{\mathrm{H}} Y_{\mathrm{H}}+\frac{t \mathcal{E} P_{\mathrm{F}}^{*}}{2}\left[\frac{\mathcal{E} P_{\mathrm{F}}^{*}(1+t)}{P_{\mathrm{T}}}\right]^{-1} C_{\mathrm{T}} \\
& =P_{\mathrm{H}} Y_{\mathrm{H}}+\frac{1}{2}\left(\frac{t}{1+t}\right) P_{\mathrm{T}} C_{\mathrm{T}},
\end{aligned}
$$


where $P_{\mathrm{T}}=\left[\mathcal{E} P_{\mathrm{F}}^{*}(1+t)\right]^{\frac{1}{2}} P_{\mathrm{H}}^{\frac{1}{2}}$ is the domestic-currency price index for tradables inclusive of the tariff's effect on import prices.

In a world equilibrium, nominal global consumer spending on Home exportables equals the receipts of Home producers, so

$$
\begin{aligned}
P_{\mathrm{H}} Y_{\mathrm{H}} & =\left[1-\frac{1}{2}\left(\frac{t}{1+t}\right)\right] P_{\mathrm{T}} C_{\mathrm{T}} \\
& =\frac{1}{2} P_{\mathrm{T}} C_{\mathrm{T}}+\frac{1}{2}\left(\mathcal{E} P_{\mathrm{F}}^{*}\right)^{\frac{1}{2}} P_{\mathrm{H}}^{\frac{1}{2}} C_{\mathrm{T}}^{*} .
\end{aligned}
$$

Solving, we find that $C_{\mathrm{T}}=(1+t)^{\frac{1}{2}} C_{\mathrm{T}}^{*}$, so that instead of eq.(10), we have the following relationship between the overall Home and Foreign expenditure levels, measured in tradables at domestic prices:

$$
Z=(1+t)^{\frac{1}{2}} Z^{*}
$$

\section{Solving for world spending and the terms of trade}

Using the deterministic version of the Foreign wage first-order condition corresponding to eq. (6), writing out $P^{*}$ in terms of its components, and using the markup condition for product prices, we derive

$$
\left(\frac{\mathcal{E} W^{*}}{W}\right)^{(1-\rho) \gamma / 2}=\left[\frac{\phi \theta}{(\phi-1)(\theta-1)}\right] K^{*} L^{*[\nu-(1-\rho)]} .
$$

Doing the same for Home, but taking account of the tariff's effect on Home import prices and the Home consumer's budget constraint, we find

$$
\left(\frac{W}{\mathcal{E} W^{*}}\right)^{(1-\rho) \gamma / 2}=\frac{(1+t)^{(1-\rho) \gamma / 2} \phi \theta}{\left[1-\frac{\gamma t}{2(1+t)}\right]^{\rho}(\phi-1)(\theta-1)} K L^{\nu-(1-\rho)}
$$

To complete the model's solution, we need to furnish the relationships between $L$ and $Z$ and between $L^{*}$ and $Z=(1+t)^{\frac{1}{2}} Z^{*}$. From the Foreign budget constraint, $P_{\mathrm{T}}^{*} Z^{*}=\left(\frac{\theta}{\theta-1}\right) W^{*} L^{*}$, and the definition of $P_{\mathrm{T}}^{*}$, we conclude that

$$
L^{*}=\left[\frac{W}{\mathcal{E} W^{*}(1+t)}\right]^{\frac{1}{2}} Z \text {. }
$$


Since $L=Y_{\mathrm{H}}+Y_{\mathrm{N}}$, the equality of demand for and supply of total Home output leads to

$$
L=\left[\left(1-\frac{\gamma}{2}\right)(1+t)^{\frac{1}{2}}+\frac{\gamma}{2}(1+t)^{-\frac{1}{2}}\right]\left(\frac{\mathcal{E} W^{*}}{W}\right)^{\frac{1}{2}} Z
$$

Using eqs. (41) and (42) to eliminate $L^{*}$ and $L$, respectively from eqs. (39) and (40), we obtain two independent relationships that can be solved for $Z$ and $\mathcal{E} W^{*} / W$ (as we shall do explicitly later in the $t=0$ case).

\section{Solving for utility}

By combining the Home wage first-order condition and budget constraint, taking account of the tariff rebate, we find that

$$
\frac{K}{\nu} L^{\nu}=\frac{\left(\frac{\phi-1}{\phi}\right)\left(\frac{\theta-1}{\theta}\right)\left[1-\frac{\gamma t}{2(1+t)}\right]}{\nu} C^{1-\rho} .
$$

Since flex-wage utility is given by eq. (3), we may therefore write overall utility $($ as $\chi \rightarrow 0)$ as proportional to $C^{1-\rho} /(1-\rho)$ :

$$
U=\left\{\frac{\nu \phi \theta-(\theta-1)(\phi-1)(1-\rho)\left[1-\frac{\gamma t}{2(1+t)}\right]}{(1-\rho) \nu \phi \theta}\right\} C^{1-\rho}
$$

Noting that

$$
C=\left[\frac{\mathcal{E} W^{*}(1+t)}{W}\right]^{(1-\gamma) / 2} Z,
$$

we see from the purely multiplicative role of terms involving $t$ in eqs. (39)(41) and (43) that we may write flex-wage utility in the presence of a nonzero tariff $t, \tilde{U}(t)$, as

$$
\tilde{U}(t)=\Psi(t) \tilde{U}(0)
$$

where $\tilde{U}(0)=\tilde{U}$, in terms of our earlier notation, and $\Psi(t)$ is a complicated function of the tariff rate.

\section{The flexible-wage zero-tariff solution}

With zero tariffs, the symmetry of the equilibrium leads to a quick solution. Equations (39)-(42) imply that the equilibrium terms of trade are

$$
\frac{\mathcal{E} W^{*}}{W}=\left(\frac{K^{*}}{K}\right)^{\frac{1}{\nu-(1-\gamma)(1-\rho)}}
$$




$$
Z=\left[\frac{(\phi-1)(\theta-1)}{\phi \theta\left(K K^{*}\right)^{\frac{1}{2}}}\right]^{\frac{1}{\nu-(1-\rho)}} .
$$

These equations are easily combined with the equations for the ex post stickywage values of $z$ and $e$, eqs. (15) and (16), to calculate the monetary response elasticities replicating the flexible-wage equilibrium, eqs. (29) and (30).

We may also calculate

$$
\tilde{U}=\left[\frac{\nu \phi \theta-(\theta-1)(\phi-1)(1-\rho)}{(1-\rho) \nu \phi \theta}\right] C^{1-\rho}
$$

where

$$
\begin{aligned}
C^{1-\rho} & =\left[\frac{\mathcal{E} W^{*}(1+t)}{W}\right]^{(1-\gamma)(1-\rho) / 2} Z^{1-\rho} \\
& =\left(\frac{K^{*}}{K}\right)^{\frac{(1-\gamma)(1-\rho)}{2[\nu-(1-\gamma)(1-\rho)]}}\left[\frac{(\phi-1)(\theta-1)}{\phi \theta\left(K K^{*}\right)^{\frac{1}{2}}}\right]^{\frac{1-\rho}{\nu-(1-\rho)}}
\end{aligned}
$$

Using the last equations, we also find expected utility under wage flexibility, $\mathrm{E} \tilde{U}$ :

$$
\begin{aligned}
\mathrm{E} \tilde{U}= & {\left[\frac{\nu \phi \theta-(\theta-1)(\phi-1)(1-\rho)}{(1-\rho) \nu \phi \theta}\right]\left[\frac{(\phi-1)(\theta-1)}{\phi \theta}\right]^{\frac{1-\rho}{\nu-(1-\rho)}} \bullet } \\
& \exp \left\{-\frac{(1-\rho) \mathrm{E} \kappa}{\nu-(1-\rho)}+\frac{(1-\rho)^{2} \sigma_{\kappa}^{2}}{2[\nu-(1-\rho)]^{2}}\right. \\
\left.-\frac{(1-\rho)^{2} \gamma \nu\left[\left(1-\frac{\gamma}{2}\right) \nu-(1-\gamma)(1-\rho)\right]}{[\nu-(1-\rho)]^{2}[\nu-(1-\gamma)(1-\rho)]^{2}} \sigma_{\kappa_{d}}^{2}\right\} & {\left[\frac{\nu \phi \theta-(\theta-1)(\phi-1)(1-\rho)}{(1-\rho) \nu \phi \theta}\right]\left[\frac{(\phi-1)(\theta-1)}{\phi \theta}\right]^{\frac{1-\rho}{\nu-(1-\rho)}} \bullet } \\
& \exp \left\{-\frac{(1-\rho) \mathrm{E} \kappa}{\nu-(1-\rho)}+\frac{(1-\rho)^{2} \sigma_{\kappa}^{2}}{2[\nu-(1-\rho)]^{2}}-\frac{(1-\rho) \lambda}{\nu-(1-\rho)}\right\} .
\end{aligned}
$$

This formula corresponds to eq. (24) in the text. 